\title{
0115 HEALTH SYSTEM PREPAREDNESS FOR ROAD TRAFFIC ACCIDENTS IN A RURAL DISTRICT IN KERALA, INDIA
}

B M Asheel*, B Soman, V G Kuriakose, S Francis, T Mathew Correspondence: Achutha Menon Centre for Health Science Studies, SCTIMST, Zainaba Manzil, Near Juma Masjid, Edat (P0), Payyannur, Kannur (dist), Kerala 670327, India

10.1136/ip.2010.029215.115

Objectives To assess the health system preparedness with regard to road traffic accidents, in terms of resources, organisational functions and geographical distribution of trauma care facilities and their proximity to accident prone areas in Alappuzha district, Kerala.

Methods The WHO Guidelines for Essential Trauma Care was used for this descriptive operational research involving 49 hospitals in Alappuzha district. Site visits were done (Jul-Sep 2009) for direct inspection and interviews with administrative and clinical staff. The geo-spatial data collected was analysed using ArcGIS version 9.1 and adequacy of resources analysed using SPSS version 17.0.

Results None of the hospitals at any level had adequate physical or human resources deemed essential at that level as per the guidelines. Though essential physical resources for emergency resuscitation of accident victims were adequate at tertiary level, these were found inadequate $(82.4 \%)$ or absent $(11.8 \%)$ even at specialty hospital. In all settings there was a dearth of administrative functions to ensure quality trauma care. Geo spatial analysis showed that $67 \%$ of accident prone areas fell within 10 min travel time by an ambulance, to a specialist hospital and $76.5 \%$ of specialist hospital falls within $1 \mathrm{~h}$ travel time to tertiary hospital.

Conclusion Trauma care preparedness of Alappuzha district was found to be dismally poor. The study identified critical resources which if provided would improve the trauma care preparedness in the district several folds without much financial investment. This may suit to similar political and resource poor settings else were. 